\title{
Mineração da interação genótipo x ambiente em Phaseolus vulgaris L. para o Estado de Santa Catarina
}

\author{
Mining of genotype $x$ environment interaction in Phaseolus vulgaris $L$. to the State of Santa Catarina
}

\author{
Jefferson Luís Meirelles Coimbra ${ }^{*}$ Juliano Garcia Bertoldo ${ }^{\mathrm{I}}$ Haroldo Tavares Elias ${ }^{\mathrm{II}}$ \\ Silmar Hemp ${ }^{\mathrm{II}}$ Naine Martins do Vale ${ }^{\mathrm{I}}$ Diego Toaldo ${ }^{\mathrm{I}}$ Fabiani da Rocha ${ }^{\mathrm{I}}$ Leiri Daine Barili ${ }^{\mathrm{I}}$ \\ Soraya Helena Garcia' Altamir Frederico Guidolin' ${ }^{\mathrm{I}}$ Mauricio Marini Kopp ${ }^{\mathrm{III}}$
}

RESUMO

Genótipos de feijão (Phaseolus vulgaris L.) dos grupos preto (testados em seis ambientes) e carioca (testados em cinco ambientes) foram avaliados para rendimento de grãos na safra agrícola de 2006/07, no Estado de Santa Catarina. Desse modo, o objetivo deste trabalho foi avaliar a sensibilidade genotípica, por meio de funções preditas entre a diferença do potencial rendimento de grãos médio $\left(\mathrm{kg} \mathrm{ha}^{-1}\right)$, considerando todas as combinações possíveis entre os ambientes estudados. Ausência de significância para todos os genótipos testados de feijão preto indica um comportamento insensível destes genótipos frente às variações do par de ambiente Chapecó versus Lages. Por outro lado, o ambiente de Ponte Serrada, independentemente do grupo (preto ou carioca) e do outro ambiente de cultivo, afetou intensamente todas as funções preditas, indicando que estes genótipos devem ser recomendados para cultivo em ambientes estratificados.

Palavras-chave: variância fenotípica, BLUP, sensibilidade, rendimento de grãos de feijão.

\section{ABSTRACT}

Common bean genotypes (Phaseolus vulgaris $L$.) belonging to the black group (evaluated in six environments) or to the 'carioca' group (evaluated in five environments) were tested for grain yield in the season of 2006/07, in the Santa Catarina State. The objective of this study was to evaluated the genotypic sensibility through predicted functions among the differences of the grain yield considering all the possible combinations among the studied environments. Significance absence for all tested genotypes of the black group indicates an insensitive behavior of these genotypes relatively to the pair of environment Chapecó vs. Lages. On the other hand, the Ponte Serrada environment intensely affected all the predicted functions relatively to the other environments regardless of bean group (black or carioca), indicating that these genotypes should be recommended for cultivation in stratified environments.

Key words: phenotypic variance, BLUP, sensibility, grain yield bean.

\section{INTRODUÇÃO}

O feijão comum (Phaseolus vulgaris L.) é cultivado em mais de $90 \%$ das áreas do mundo (GONZÁLEZ et al., 2006). De acordo com estes autores, é a terceira leguminosa, utilizada como alimento, mais importante do mundo, sendo ultrapassada somente pela soja (Glycine Max L.) e pelo amendoim (Arachis hypogea $\mathrm{L}$.). O feijão possui uma ampla área de cultivo no território brasileiro, sendo uma espécie cujo desempenho é altamente influenciado pelas condições de ambiente, o que resulta em produtividade média instável ao longo dos anos. As oscilações observadas nos níveis de produtividade refletem, principalmente, a sensibilidade dos genótipos às variações de ambiente. Certamente, esse fato é um dos principais motivos pelo qual o rendimento médio grãos persiste, há muitos anos, na faixa de $550 \mathrm{~kg} \mathrm{ha}^{-1}$ (ELIAS et al., 1999; BACKES et al., 2005). No entanto, a produtividade média de $940 \mathrm{~kg} \mathrm{ha}^{-1}$ de grãos de feijão no Brasil (IBGE, 2008) provavelmente tenha origens mais complexas,

\footnotetext{
IPrograma de Pós-graduação em Produção Vegetal, Universidade do Estado de Santa Catarina (UDESC). Av. Camões, 2090, Bairro Conta Dinheiro, 88520-000, Lages, SC, Brasil. E-mail: coimbrajefferson@cav.udesc.br. *Autor para correspondência.

IEpagri/Centro de Pesquisa para Agricultura Familiar, Chapecó, SC, Brasil.

IIIEmbrapa Gado de Leite, Laboratório de Biotecnologia e Fisiologia Vegetal, Juiz de Fora, MG, Brasil.
} 
como, por exemplo, doenças e baixo nível de adoção de tecnologia, como a utilização de grãos para cultivo e não de sementes, entre outras.

O efeito da interação genótipo $\mathrm{x}$ ambiente descreve o comportamento diferencial dos genótipos frente aos ambientes contrastantes. O efeito da interação genótipo $\mathrm{x}$ ambiente pode levar os diferentes genótipos avaliados a uma diversidade enorme de padrões e resultados. Porém, os pesquisadores ainda têm uma compreensão limitada das conseqüências desses tipos de padrões de adaptabilidade e de estabilidade fenotípica, dificultando a sua aplicação como critério de recomendação regionalizada de cultivares superiores pelo Ministério da Agricultura, Pecuária e Abastecimento (MAPA). Recentemente, pesquisa a respeito da interação genótipo $\mathrm{x}$ ambiente revelou uma notável inconstância na eficiência de diferentes métodos para obtenção de estimativas dos parâmetros de adaptabilidade e de estabilidade em feijão (OLIVEIRA et al., 2006).

Atualmente, há mais de duas dezenas de metodologias de análises de adaptabilidade e de estabilidade fenotípica destinadas a avaliar os genótipos frente aos diferentes ambientes. Entre os métodos existentes, o proposto por EBERHART \& RUSSEL (1966) é um dos mais utilizados pelos melhoristas de plantas. No entanto, vários autores indicam deformidades dessa metodologia, tais como: se o efeito da interação for significativo, isso implica que, pelo menos, um dos componentes (linear - $b_{i}$ e o não-linear - $\mathrm{S}_{\mathrm{di}}^{2}$ ) seja significativo, obrigatoriamente. Além disso, se apenas o componente é significativo (devido à heterogeneidade das linhas de regressão), pode-se concluir que a magnitude da interação é uma função linear do índice de ambiente para cada genótipo e que cada genótipo tem sua própria resposta linear característica à variação de ambiente (SILVA, 1995). Ainda de acordo com este autor, se o desvio é significativo, então existe ou não uma relação linear simples ou não existe qualquer relação entre a interação e o índice de ambiente. Desse modo, o modelo linear não será adequado, já que uma fração significativa da interação genótipo $\mathrm{x}$ ambiente permanece inexplicada (VERMA et al., 1978). Outras limitações que também foram mencionadas por estes últimos autores como pontos falhos da maioria dos métodos propostos de análise da estabilidade são: i) as estimativas dos parâmetros que caracterizam a estabilidade e a adaptabilidade não são independentes; ii) as médias dos genótipos contribuem para o índice de ambiente e, sendo assim, não podem ser consideradas independentes deste índice; iii) a variável independente na análise de regressão linear é função do índice de ambiente, logo estão sujeitas ao erro violando algumas pressuposições estatísticas. A principal limitação dos métodos que utilizam a regressão linear é biológica, pois justapõe as diferenças ecológicas dos distintos ambientes com o rendimento médio de grãos similar, fato que pode mascarar a resposta linear dos genótipos (KNIGHT, 1970).

Alternativamente pode ser obtida uma informação pormenorizada por meio de modelos lineares mistos quando são avaliados os efeitos do fator principal ambiente e o da interação genótipo x ambiente, por meio do melhor preditor linear não-viesado (Best Linear Unbiased Prediction - BLUP), que pode ser conceituado como uma técnica para estimar o mérito genético (ROBINSON, 1991). Motivo pertinente para se adotar um modelo linear misto é a possibilidade de se fazer a predição de fatores de efeito aleatório na presença de fatores de efeito fixo ou vice-versa, por meio do BLUP, que é de grande importância no melhoramento de plantas (McLEAN et al., 1991; ROBINSON, 1991).

O objetivo deste trabalho foi estudar a sensibilidade genotípica de genótipos de feijão dos grupos comercial preto e carioca em relação ao caráter rendimento de grãos avaliados, em diferentes ambientes no Estado de Santa Catarina.

\section{MATERIAL E MÉTODOS}

Os dados experimentais relativos ao caráter rendimento de grãos $\left(\mathrm{kg} \mathrm{ha}^{-1}\right)$ são provenientes do Ensaio Estadual de Linhagens e de Cultivares de Feijão ou do Ensaio de Valor de Cultivo e Uso, coordenados pela Empresa de Pesquisa Agropecuária e Extensão Rural de Santa Catarina (EPAGRI), de Chapecó, Santa Catariana (SC). Os ensaios foram conduzidos na safra agrícola de 2006/07, em diferentes municípios de Santa Catarina, totalizando seis locais distintos com 24 genótipos do grupo preto e cinco ambientes com 20 genótipos do grupo carioca. Os ambientes testados foram seis municípios de Santa Catarina para o grupo

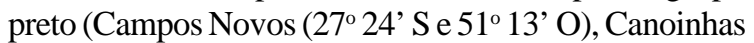

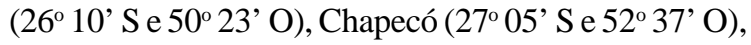
Lages ( $27^{\circ} 48^{\prime} \mathrm{S}$ e $50^{\circ} 19^{\prime} \mathrm{O}$ ), Ponte Serrada (26 $52^{\circ}$ ' S e $52^{\circ} 00^{\prime} \mathrm{O}$ ) e Xanxerê (26 $52^{\circ}$ ' S e $52^{\circ} 24^{\prime} \mathrm{O}$ )) e cinco municípios para o grupo carioca (Chapecó, Campos Novos, Canoinhas, Lages e Ponte Serrada). Os fatores climáticos ocorridos na safra agrícola de 2006/07 dos ensaios, como distribuição de chuvas e temperaturas amenas, podem ser considerados normais paras as regiões produtoras de feijão de Santa Catarina.

Foram consideradas neste trabalho todas as possíveis combinações entre os ambientes 
avaliados, sendo assim, para o grupo preto, os números significam as seguintes combinações dois a dois: i) $1=$ Campos Novos x Canoinhas, ii) 2 = Campos Novos $\mathrm{x}$ Chapecó, iii) 3 = Campos Novos x Lages, iv) 4 = Campos Novos $\mathrm{x}$ Ponte Serrada, v) 5 = Campos Novos x Xanxerê, iv) $6=$ Canoinhas $x$ Chapecó, vii) $7=$ Canoinhas $x$ Lages, viii) $8=$ Canoinhas $\mathrm{x}$ Ponte Serrada, ix) $9=$ Canoinhas $\mathrm{x}$ Xanxerê, x) 10 = Chapecó $\mathrm{x}$ Lages, xi) 11 = Chapecó $\mathrm{x}$ Ponte Serrada, xii) 12 = Chapecó x Xanxerê, xiii) $13=$ Lages x Ponte Serrada, xiv) 14 = Lages x Xanxerê e, xv) 15 = Ponte Serrada $\mathrm{x}$ Xanxerê (Figura 1). Do mesmo modo, todas as possíveis combinações entre os ambientes avaliados para o grupo carioca exprimem os pares de ambientes testados dois a dois: i) 1 = Chapecó x Campos Novos, ii) 2 = Chapecó x Canoinhas, iii) 3 = Chapecó x Lages, iv) 4 = Chapecó x Ponte Serrada, v) 5 $=$ Campos Novos $\mathrm{x}$ Canoinhas, iv) $6=$ Campos Novos $\mathrm{x}$ Lages, viii) $7=$ Campos Novos $\mathrm{x}$ Ponte Serrada, ix) $8=$ Canoinhas x Lages, x) 9 = Canoinhas x Ponte Serrada, xi) $10=$ Lages $x$ Ponte Serrada (Figura 2).

Todos os ensaios foram instalados em delineamento experimental de blocos completos casualizados com quatro repetições por tratamento. $\mathrm{O}$ rendimento de grãos foi transformado em $\mathrm{kg} \mathrm{ha}^{-1}$ a partir da área útil das parcelas $\left(3,6 \mathrm{~m}^{2}\right)$. A unidade experimental foi composta por quatro linhas de quatro metros com espaçamento entre linhas de $0,45 \mathrm{~m}$ e densidade de semeadura de 15 sementes viáveis por metro linear. As adubações de semeadura e de cobertura foram realizadas de acordo com a análise química do solo.

Os dados de rendimento de grãos foram submetidos à análise de variância, considerando o efeito de genótipo e de ambiente aleatórios, sendo realizadas duas análises independentes, uma para o grupo preto e outra análise para o grupo carioca. A análise conjunta incluiu todos os ambientes estudados. A média do rendimento de grãos dos 24 e dos 20 genótipos avaliados, nos respectivos ambientes, foi comparada pelo teste $F$ de acordo com as funções testadas, combinando sempre o mesmo genótipo em todos os pares de ambientes testados. A homogeneidade de variância e a normalidade dos dados foram verificadas por meio dos testes estatísticos de Bartlett e Shapiro-Wilk, respectivamente. Além disso, estas funções foram estimadas conforme metodologia proposta por McLEAN et al. (1991), com base no espaço de inferência, utilizando o programa computacional SAS (LITTELL et al., 2006).

\section{RESULTADOSE DISCUSSÃO}

Nos Ensaios de Valor de Cultivo e Uso (VCU) de feijão, o rendimento médio de grãos obtido pelos genótipos dos grupos preto (3.074kg ha-1) e carioca (3.586 $\mathrm{kg} \mathrm{ha}^{-1}$ ) mostra um desempenho promissor, possibilitando a recomendação regionalizada dos genótipos testados em relação aos ambientes de cultivo avaliados.

Na tabela 1, pode ser observado o valor dos componentes de variância em feijão dos grupos preto e carioca obtido para o caráter rendimento de grãos. O objetivo mais relevante para a utilização do modelo aleatório é a estimação dos componentes da variância que estão ligados diretamente às estimativas dos parâmetros genéticos, como, por exemplo, o coeficiente de herdabilidade.

A estimação dos componentes da variância possibilita o melhor conhecimento da variabilidade genética dos genótipos, o que permite a previsão dos ganhos com a seleção de plantas geneticamente superiores. Assim, métodos de seleção mais eficientes e menos onerosos podem ser utilizados para maximizar esses ganhos. Para tanto, as estimativas das contribuições individuais de cada componente (o efeito de genótipo, de ambiente e da interação genótipo $\mathrm{x}$ ambiente) na constituição fenotípica podem ser obtidas. A predição de valores genéticos e os métodos de seleção dependem, essencialmente, de estimativas de componentes de variância (SMITH et al., 2001). Fato este que torna evidente que a predição dos parâmetros genéticos, como, por exemplo, o coeficiente de herdabilidade tanto no sentido amplo quanto restrito tem sentido apenas para efeitos aleatórios.

Ao serem analisados os componentes da variância fenotípica (Tabela 1), é possível visualizar que a grande variação entre as médias marginais dos genótipos avaliados deve ser atribuída à variância do ambiente tanto para o grupo preto $\left(\sigma^{2}=1.570 .078\right)$ quanto para o grupo carioca $\left(\sigma^{2}=1.378 .770\right)$, sendo a estimativa da contribuição genotípica tanto para o grupo preto $(23,67)$ quanto para o grupo carioca $(13,74)$ de menor magnitude. Desse modo, a grande oscilação na expressão do fenótipo pode ser justificada pelo fato de que o caráter rendimento de grãos é de natureza estritamente quantitativa, ou seja, determinando, assim, que a expressão deste caráter está fortemente ligada à expressão de vários genes e de pequeno efeito sobre o fenótipo. Outro fato que também explica este valor baixo para o componente da variância para o fator genótipo é a estreita base genética que os diferentes Programas de Melhoramento de Feijão do Brasil evidenciam, principalmente, no final do processo de seleção de linhagens superiores. Para VIEIRA et al. (2001), as cultivares de feijão atualmente semeadas no Brasil apresentam uma base genética muito estreita, o que é comum entre variedades comerciais. Este grau de 


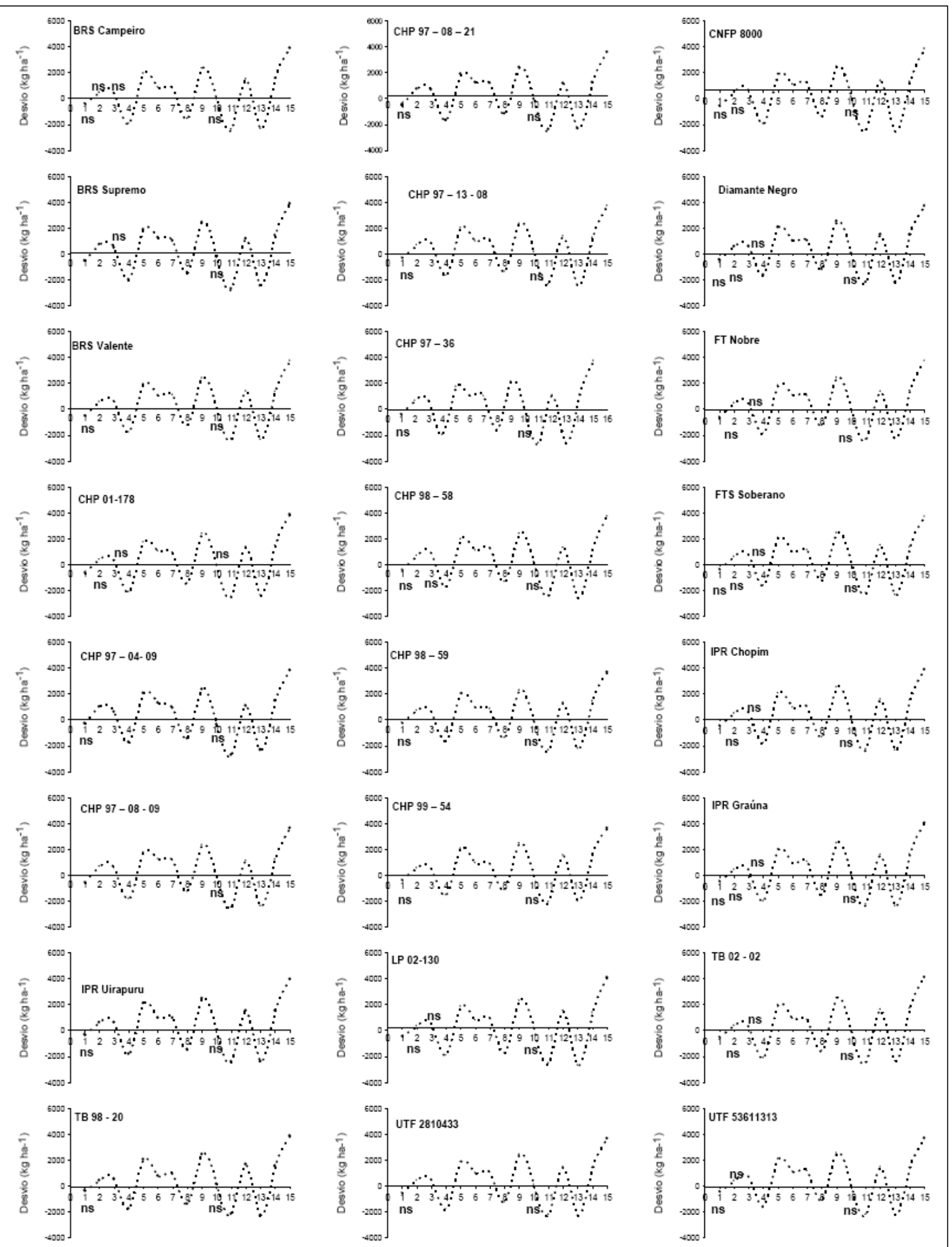

Figura 1 - Desvio do comportamento genotípico de 24 genótipos de feijão-preto comparados em seis ambientes distintos, combinados dois a dois, avaliado por meio do Ensaio Estadual de Linhagens e Cultivares de feijão de Santa Catarina. Lages, SC, 2008. 


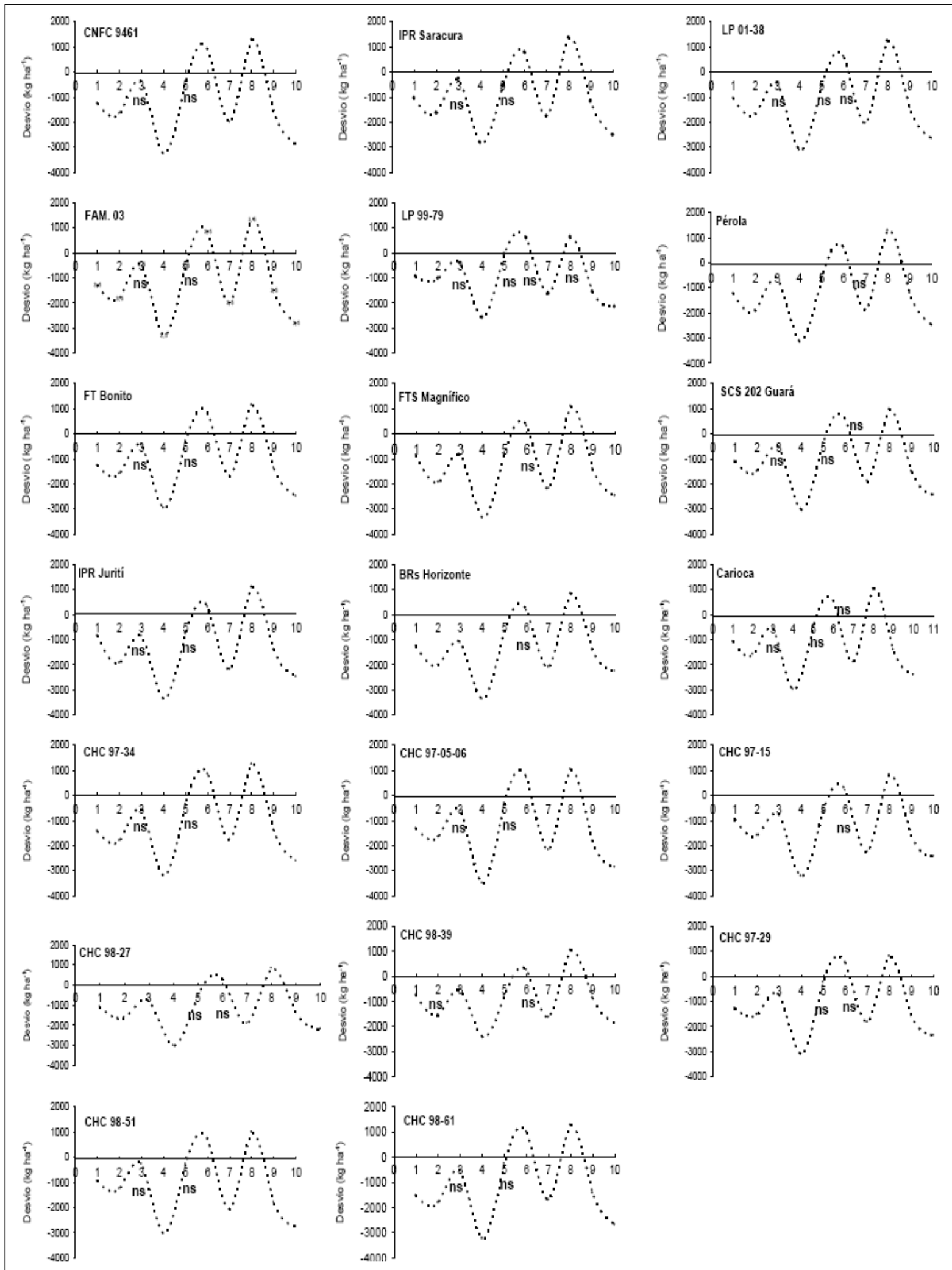

Figura 2 - Desvio do comportamento genotípico de 20 genótipos de feijão-carioca em relação ao caráter rendimento de grãos avaliados em cinco ambientes distintos, testados dois a dois, pertencentes ao Ensaio Estadual de linhagens e cultivares de feijão de Santa Catarina. Lages, SC, 2008. 
Tabela 1 - Componentes de variância (CV) para o caráter rendimento de grãos dos efeitos aleatórios para o Ensaio Estadual de linhagens e cultivares de feijão-preto e feijão-carioca. Lages, SC, 2008.

\begin{tabular}{|c|c|c|c|c|}
\hline \multirow{2}{*}{$\mathrm{CV}$} & \multicolumn{2}{|c|}{ 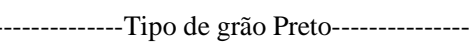 } & \multicolumn{2}{|c|}{------------Tipo de grão Carioca----------- } \\
\hline & Estimativas & Erro Padrão & Estimativas & Erro Padrão \\
\hline Ambiente (A) & 1.570 .078 & 995.155 & 1.378 .770 & 978.418 \\
\hline Genótipo (G) & 23.677 & 11.131 & 13.741 & 11.306 \\
\hline$A * G$ & 28.891 & 11.315 & 48.003 & 16.489 \\
\hline Resíduo & 210.036 & 14.303 & 201.697 & 16.468 \\
\hline
\end{tabular}

variabilidade genética restrita é imposto tanto pelo agricultor quanto pelo consumidor, pois todas essas cadeias produtivas têm preferência por um ideótipo de planta determinando, representando assim, um gargalo na variabilidade genética dessa cultura.

Na situação de variabilidade genética limitada, principalmente para o caráter rendimento de grãos, as estimativas dos efeitos dos valores genotípicos de feijão do grupo preto e do carioca não seriam coerentes com qualquer variação entre estas constituições genotípicas. Portanto, a abordagem de modelos lineares mistos mostra-se coerente com a realidade e, por isso, é tida como conceitualmente mais completa e muito mais informativa (PIEPHO \& MÖHRING 2005; PIEPHO, 1999). De modo prático, pode ser concluído que, mesmo quando a variabilidade genética é estreita, a metodologia dos modelos lineares mistos pode gerar informações notadamente diferentes em relação às metodologias clássicas de avaliação da interação genótipo $\mathrm{x}$ ambiente, com base na regressão linear simples ou na regressão bissegmentada, por exemplo.

$\mathrm{Na}$ estimativa dos coeficientes da herdabilidade, os dois grupos não divergiram, pois ambos apresentaram valores baixos. As estimativas para coeficiente de herdabilidade foram 0,21 e 0,12 para o grupo comercial preto e o grupo carioca, respectivamente. Tais resultados revelam que o valor da herdabilidade para o caráter rendimento de grãos é baixo. Este valor estimado foi obtido principalmente pelos altos valores estimados para a contribuição do ambiente, evidenciando que este caráter sofre uma forte influência do ambiente, reduzindo, assim, a correlação linear simples entre o valor fenotípico e genotípico. De acordo com FALCONER \& MACKAY (1996), o caráter rendimento de grãos é governado por vários genes de pequeno efeito sobre o fenótipo, classificando este caráter como quantitativo. Para COIMBRA et al. (1999), o rendimento de grãos é um caráter complexo, resultante dos efeitos multiplicativos de seus componentes tanto primários quanto secundários. Freqüentemente, os caracteres controlados por vários genes e fortemente influenciados pela ação do ambiente apresentam valores de herdabilidade baixo (LI et al., 2003). De acordo com estes autores supracitados, os caracteres de herança complexa apresentam baixa herdabilidade e elevada interação com o ambiente, dificultando assim a seleção de genótipos superiores geneticamente. Assim, a seleção para o caráter rendimento de grãos pode ser dificultada em programas de melhoramento devido ao alto valor da contribuição da variância de ambiente estimado em associação com o baixo coeficiente de herdabilidade observado, reduzindo a correlação entre o fenótipo e o genótipo.

Na tabela 2 são apresentados o efeito genotípico e o valor genotípico dos 24 genótipos do grupo preto e dos 20 genótipos do grupo carioca. Para facilitar a interpretação destes valores, a cada um desses desvios foi acrescentada a média geral (média do modelo) apenas para que os valores fossem expressos em $\mathrm{kg} \mathrm{ha}^{-1}$, unidade amplamente difundida. Observando esta estimativa, pode ser notado um comportamento bastante peculiar para alguns genótipos de feijão preto e carioca avaliados, como, por exemplo, para os genótipos do grupo preto TB 0202 (231) e BRS Valente (-261) e para genótipos do grupo carioca LP 0138 (160) e BRS Horizonte (-121). Interpretando este efeito genotípico, pode-se afirmar que valor com sinal positivo indica que o referido genótipo contribui para o incremento da média geral do ensaio, enquanto que o valor com sinal negativo indica que o genótipo reduziu a média geral. Assim, o genótipo TB 202 aumenta sua média geral em mais de $230 \mathrm{~kg} \mathrm{ha}^{-1}$, aproximadamente. Por outro lado, o genótipo BRS Horizonte reduz em $121 \mathrm{~kg} \mathrm{ha}^{-1}$ a média geral. Este desvio ou efeito genotípico contém somente a informação relativa ao efeito aleatório do fator genótipo, ou seja, é a média dos efeitos genotípicos estimados por ambientes. LITTELL et al. (2006) demonstraram como os valores de funções preditas, por exemplo, as médias experimentais das progênies aleatórias mudam quando a magnitude dos componentes de variâncias é modificada. O interesse pela informação relacionada ao componente de variância 
Tabela 2 - Efeito genotípico (EG) e valor genotípico (VG) estimados para o caráter rendimento de grãos por meio do Ensaio Estadual de Linhagens e Cultivares de feijão-preto e feijão-carioca de Santa Catarina. Lages, SC, 2008.

\begin{tabular}{|c|c|c|c|c|c|}
\hline \multirow{2}{*}{ Genótipo } & \multicolumn{2}{|c|}{--------------Tipo Preto---------------' } & \multirow{2}{*}{ Genótipo } & \multicolumn{2}{|c|}{----------Tipo Carioca---------- } \\
\hline & E.G & V.G (kg ha-1) & & E.G & V.G $\left(\mathrm{kg} \mathrm{ha}^{-1}\right)$ \\
\hline BRS Campeiro & 107,6 & 3.181 & BRS Horizonte & $-121,49$ & 3.465 \\
\hline BRS Supremo & 153,2 & 3.226 & Carioca & $-0,44$ & 3.586 \\
\hline BRS Valente & $-260,7$ & 2.812 & CHC 97-05-06 & $-31,04$ & 3.555 \\
\hline CHP 01-178 & $-94,9$ & 2.978 & CHC 97-15 & 4,63 & 3.591 \\
\hline CHP 97-04-09 & 152,9 & 3.226 & CHC 97-29 & 106,63 & 3.693 \\
\hline CHP 97-08-09 & 27,0 & 3.100 & CHC 97-34 & 60,05 & 3.646 \\
\hline CHP 97-08-21 & 116,1 & 3.189 & CHC 98-27 & $-102,84$ & 3.483 \\
\hline CHP 97-13-08 & $-43,1$ & 3.030 & CHC 98-39 & $-76,17$ & 3.510 \\
\hline CHP 97-36 & $-128,4$ & 2.945 & CHC 98-51 & $-46,03$ & 3.540 \\
\hline CHP 98-58 & 16,0 & 3.089 & CHC 98-61 & 32,53 & 3.619 \\
\hline CHP 98-59 & 28,2 & 3.101 & CNFC 9461 & 81,31 & 3.667 \\
\hline CHP 99-54 & $-40,9$ & 3.032 & FAM.03 & $-37,14$ & 3.549 \\
\hline CNFP 8000 & $-22,2$ & 3.051 & FT Bonito & $-97,57$ & 3.488 \\
\hline Diamante Negro & $-210,2$ & 2.863 & FTS Magnífico & $-10,48$ & 3.576 \\
\hline FT Nobre & $-54,7$ & 3.018 & IPR Juriti & 84,51 & 3.671 \\
\hline FTS Soberano & $-134,2$ & 2.939 & IPR Saracura & 2,22 & 3.588 \\
\hline IPR Chopim & $-51,9$ & 3.021 & LP 01-38 & 159,65 & 3.746 \\
\hline IPR Graúna & 150,2 & 3.223 & LP 99-79 & 18,36 & 3.604 \\
\hline IPR Uirapuru & $-30,2$ & 3.043 & Pérola & $-68,59$ & 3.517 \\
\hline LP 02-130 & 166,0 & 3.239 & SCS 202 Guará & 41,90 & 3.628 \\
\hline ТВ 02-02 & 231,4 & 3.304 & -- & -- & -- \\
\hline ТВ 98-20 & $-39,0$ & 3.034 & -- & -- & -- \\
\hline UTF 2810433 & $-28,2$ & 3.045 & -- & -- & -- \\
\hline Média & -- & 3.074 & -- & -- & 3.586 \\
\hline
\end{tabular}

genotípica é, portanto, imediato, uma vez que tem relação direta com o potencial genético.

A figura 1 apresenta o comportamento genotípico de 24 genótipos de feijão do grupo preto que permite estimar a sensibilidade do potencial de rendimento de grãos de determinado genótipo avaliado num par de ambiente específico. Pode ser observada uma grande similaridade quanto ao desempenho dos genótipos de feijão do grupo preto, de modo que todos os genótipos avaliados revelam uma consistência ou uma insensibilidade quanto ao rendimento de grãos quando cultivados no par de ambientes de Chapecó e Lages (número 10). Do mesmo modo, os genótipos de feijão BRS Campeiro, IPR Graúna, LP 02-130 e TB 98-20 apontam uma consistência frente a quase todos os ambientes avaliados (Campos Novos, Canoinhas, Chapecó e Lages), ou seja, estes genótipos podem ser cultivados em qualquer um desses ambientes sem sofrer alterações significativas no rendimento de grãos. Isso caracteriza estes genótipos como insensíveis às variações frente a diferentes macrorregiões do Estado de Santa Catarina. Observando ainda a figura 1 pode ser notado que nenhum genótipo avaliado apresentou um comportamento previsível frente aos ambientes de Ponte Serrada e Xanxerê, quando combinados com os demais ambientes avaliados. Por exemplo, para o genótipo BRS Campeiro, quando avaliado no par de ambientes de Campos Novos versus Ponte Serrada (número 4), revela um rendimento de grãos de $1.959 \mathrm{~kg}$ ha-1 ${ }^{-1}$ inferior à média geral, ou seja, este genótipo aponta um desempenho superior ao ambiente de Campos Novos em termos de rendimento de grãos. Do mesmo modo, quando este mesmo genótipo é cultivado nos ambientes de Campos Novos versus Xanxerê (número 5), revela um rendimento de grãos de $1.925 \mathrm{~kg} \mathrm{ha}^{-1}$, já nos ambientes de Ponte Serrada versus Xanxerê (número 15) o potencial de rendimento de grãos passa para $3.885 \mathrm{~kg} \mathrm{ha}^{-1}$.

Outra informação extremamente útil em termos de melhoramento genético vegetal é distinguir em quais ambientes o melhorista pode conduzir e avaliar suas populações segregantes sem que haja uma interferência forte em termos de fenótipo ocasionada pelo efeito não-genético, ou seja, de ambiente. Assim sendo, pode-se afirmar que os ambientes de Chapecó e de Lages modificaram o valor fenotípico de todos os 
genótipos avaliados do grupo preto de forma similar. Já dos 24 genótipos avaliados no par de ambientes de Campos Novos versus Canoinhas (número 1), 67\% entre eles revelaram um comportamento insensível frente a este par de ambientes. Estas funções estimadas variaram de $2.739 \mathrm{~kg} \mathrm{ha}^{-1}$ a $4.085 \mathrm{~kg} \mathrm{ha}^{-1}$, de modo que fica evidente a ampla variação do potencial de rendimento de grãos em relação aos distintos ambientes. Segundo PIEPHO (1994) e PIEPHO (1999), isso pode ser contornado facilmente com o emprego de modelos lineares mistos, por meio da decomposição do componente de variância em efeitos específicos para cada ambiente (médias incondicionais). Para alguns autores, esse tipo de estabilidade não é desejável agronomicamente porque o desempenho do genótipo não acompanha a melhoria do ambiente e, além disso, normalmente a estabilidade está associada a uma menor produtividade de grãos, especialmente nos ambientes mais favoráveis (RAMALHO et al., 1993).

Os gráficos inseridos na figura 2 descrevem o desvio do comportamento genotípico de 20 genótipos de feijão do grupo carioca em relação ao caráter rendimento de grãos avaliados em cinco ambientes distintos, testados dois a dois, pertencentes ao Ensaio Estadual de Linhagens e de Cultivares, sendo que, dos 20 genótipos, mais da metade (11 genótipos) revelaram uma insensibilidade genotípica em relação aos ambientes de Campos Novos e de Lages (número 6). Novamente todos os genótipos de feijão do grupo carioca apontaram uma alteração no seu potencial produtivo frente ao ambiente de Ponte Serrada em relação aos demais ambientes testados, corroborando o desempenho obtido entre genótipos de feijão do grupo preto (Figura 1). Tal fato pode ser explicado, todavia nenhum dos ambientes avaliados neste estudo apresenta uma condição de cultivo tão favorável à cultura do feijão independente do grupo avaliado, comparativamente ao do ambiente Ponte Serrada. De modo geral, o desempenho dos genótipos atualmente cultivados em Santa Catarina pode ser considerado insensível ou adaptado na grande maioria dos ambientes do Estado que cultivam feijão. Por outro lado, estes genótipos, quando cultivados em ambientes altamente favoráveis, logicamente não conseguem manter o mesmo potencial de rendimento quando cultivados em outros ambientes menos favoráveis. No entanto, há carência de estudos sobre a adaptabilidade e a estabilidade de cultivares de feijão no Estado de Santa Catarina (BACKES et al., 2005).

Pode ser corroborada a grande utilidade e a eficiência desse tipo de análise tanto na recomendação de genótipos quanto na seleção de ambientes capazes de manter ou melhorar o desempenho produtivo. Este procedimento permite a seleção de genótipo com valores genéticos proeminentes, independentemente do ambiente, sendo esta a estratégia mais plausível em termos de seleção de genótipos superiores frente aos diferentes ambientes, em detrimento da avaliação apenas pelo valor fenotípico, conforme a maioria dos modelos de análise de estabilidade e adaptabilidade.

\section{CONCLUSÃO}

Os genótipos de feijão avaliados no Ensaio Estadual de Linhagens e Cultivares revelam uma estreita variabilidade genética para o caráter rendimento de grãos, essencialmente os genótipos com grãos do tipo carioca. Independentemente do grupo, todos os genótipos mostram um rendimento de grãos insensível aos ambientes de Campos Novos versus Lages.

\section{REFERÊNCIAS}

BACKES, R.L. et al. Adaptabilidade e estabilidade de genótipos de feijoeiro no estado de Santa Catarina. Acta Scientiarum Agronomy, v.27, n.2, p.309-314, 2005.

COIMBRA, J.L.M. et al. Parâmetros genéticos do rendimento de grãos e seus componentes com implicações na seleção indireta em genótipos de feijão preto. Ciência Rural, v.29, n.1, p.16, 1999.

EBERHART, S.A.; RUSSELL, W.A. Stability parameters for comparing varieties. Crop Science, v.6, p.36-40, 1966.

ELIAS, H.T. et al. Análise da interação genótipo x ambiente na avaliação de cultivares de feijão em Santa Catarina. Pesquisa Agropecuária Gaúcha, v.5, n.2, p.271-275, 1999.

FALCONER, D.S.; MACKAY, T.F.C. Introduction to quantitative genetics. 4.ed. England: Longman, 1996. 463p.

GONZÁLEZ, A.M. et al. Genetic variation and environmental effects on agronomical and commercial quality traits in the main European market classes of dry bean. Field Crops Research, v.95, n.2-3, p.336-347, 2006.

IBGE. Instituto Brasileiro de Geografia e Estatística. Brasília, julho, 2008. Capturado em 28 jul. 2008. Online. Disponível na Internet http://www.ibge.gov.br/home/.

KNIGHT, R. The measurement and interpretation of genotypeenvironment interaction. Euphytica, v.19, p.225-235, 1970.

LI, Z.K. et al. Qtl x environment interactions in rice. I. Heading date and plant height. Theoretical Applied of Genetics, v.108, p.141-153, 2003.

LITTELL, R.C. et al. SAS for mixed models. 2.ed. Cary, NC, 2006. 834p.

McLEAN, R.A. et al. A unified approach to mixed model theory. American Statistician, v.45, n.1, p.54-64, 1991. 
OLIVEIRA, E.J. et al. Adaptabilidade e estabilidade de genótipos de amendoim de porte rasteiro. Pesquisa Agropecuária Brasileira, v.41, n.8, p.1253-1260, 2006.

PIEPHO, H.P. Best linear unbiased prediction (BLUP) for regional yield trials: a comparison to additive main effects and multiplicative interaction (AMMI) analysis. Theoretical Applied of Genetics, v.89, n.5, p.647-654, 1994.

PIEPHO, H.P. Stability analysis using the SAS system. Agronomy Journal, v.91, n.1, p.154-160, 1999.

PIEPHO, H.P.; MÖHRING, J. Best linear unbiased prediction of cultivar effects for subdivided target regions. Crop Science, v.45, n.3, p.1151-1159, 2005.

RAMALHO, M.A.P. et al. Genética quantitativa em plantas autógamas: aplicações ao melhoramento do feijoeiro. Goiânia: UFG, 1993. 271p.
ROBINSON, G.K. That blup is a good thing: the estimation of random effects. Statistical Science, v.6, n.1, p.15-51, 1991.

SILVA, J.G.C. Análise da estabilidade através de regressão linear segmentada. I. Fundamentos. Pesquisa Agropecuária Brasileira, v.30, n.4, p.435-448, 1995.

SMITH, A. et al. Analyzing variety by environment data using multiplicative mixed models and adjustments for spatial field trend. Biometrics, v.57, n.4, p.1138-1147, 2001.

VERMA, M.M. et al. Limitations of conventional regression analysis: a proposed modification. Theoretical and Applied Genetics, v.53, n.2, p.89-91, 1978.

VIEIRA, E.S.N. et al. Similaridade genética entre cultivares de feijão do grupo carioca por meio de marcadores moleculares de proteínas e enzimas visando à certificação da pureza genética. Revista Brasileira de Sementes, v.23, p.35-42, 2001. 